\title{
The Fracture of Austenitic and Martensitic Steel in Liquid Lithium
}

\author{
H.U. Borgstedt, M. Grundmann \\ Kernforschungszentrum Karlsruhe GmbH, Institute for Materials and Solid State Research, \\ Postfach 3640, D-7500 Karlsruhe 1, Germany
}

Abstract

The austenitic steel 1.4301 and the martensitic stee1s $1.4914,1.4923$ are tested in liquid lithium to examine the possibility of a liquid metal embrittlement (LME). Therefore, tensile tests were carried out with different strain rates near the melting point of the lithium. Some of the specimens of all the materials have been pre-exposed in lithium (1000 h at $\left.550^{\circ} \mathrm{C}\right)$.

Effects of different severity -decreasing ductility- were found at all the materials. The reason and the progress of this effect are discussed after examination by means of metallography and scanning electron microscope.

\section{Introduction}

The technical use of lithium in Eusion technology requires the knowledge of its compatibility with any kind of structural materials. LME is one possibility of material deterioration among others. It occurs in the vincinity of the melting point of liquid metals and results in a relative dramatic decrease of ductility, sometimes also a decrease of the mechanical properties. Since a fusion reactor will be operated in a pulsing mode, critical ranges of temperature, stresses and strains might be passed, in which the materials might be deteriorated by the reactive liquid metal.

LME is ruled by several parameters. Thus, LME is limited to some reaction couples. Results of similar experiments are not transferable /1,2/. Therefore, experiments with the steels $1.4301,1.4914$ and 1.4923 are conducted in our laboratory.

\section{Experiments}

\section{I Materials}

Following heat resistent and stainless steels are checked in respect of their embrittlement behaviour, when they are in contact with liquid lithium:

- the scc ferritic-martensitic steels

$$
\begin{aligned}
& \text { X } 22 \mathrm{CrMoV} 121 \text { with } \mathrm{T}_{\text {Hardening }}=1050{ }^{\circ} \mathrm{C}, \mathrm{t}=30 \mathrm{~min} ; \mathrm{T}_{\text {Tempering }}=700{ }^{\circ} \mathrm{C}, \mathrm{t}=2 \mathrm{~h} \text {; } \\
& \mathrm{x} 18 \mathrm{CrMoVNb} 121 \text { with } \mathrm{T}_{\mathrm{H}}=1075^{\circ} \mathrm{C}, \mathrm{t}=30 \mathrm{~min} ; \mathrm{T}_{\mathrm{T}}=700{ }^{\circ} \mathrm{C}, \mathrm{t}=2 \mathrm{~h} \text {; } \\
& \text { - the fcc austenitic steel } \\
& \mathrm{x} 5 \mathrm{CrNi} 189 \text { with } \mathrm{T}_{\mathrm{H}}=1050{ }^{\circ} \mathrm{C}, \mathrm{t}=30 \mathrm{~min} \text {. }
\end{aligned}
$$

The ferritic steels are belonging to the group of the $12 \% \mathrm{Cr}-\mathrm{stee} 1 \mathrm{~s}$. They have good mechanical and thermal properties. The Nb-stabilized steel shows an improved fatigue behaviour and better strength factors. It is very attractive as structural material of the SNR $/ 3 /$. The austenitic steel is typical for the class of $18 / 8 \mathrm{Cr}-\mathrm{Ni}-\mathrm{steels}$, which are used predominanty in the manufacture of apperatus. It is comparable to the steels AISI 304 and 316 and shows good resistence to sodium.

In the experiments two kinds of specimens ( a threaded test piece with cylindrical cross section, DIN 50125) were used. The specimens of 1.4301 and 1.4923 had the following dimension sizes: cross section $d_{0}=4 \mathrm{~mm}$, gauge length $\mathrm{L}_{\mathrm{g}}=20 \mathrm{~mm}$, total length $\mathrm{L}_{t}=76 \mathrm{~mm}$, thread head M 10; the specimen of $9.4914: \mathrm{d}_{0}=3 \mathrm{~mm}, \mathrm{~L}_{\mathrm{o}}=30 \mathrm{mn}, \mathrm{L}_{t}=56 \mathrm{~mm}$, if 5 . 


\subsection{The Lithium lietal}

Lithium with a melting point at $179^{\circ} \mathrm{C}$ is very reactive. The solubility of the transition metals in the liquid metal as well as the extent of the penetration of the alkali metal into the solid material are the relevant properties for the application in a fusion reactor. The contents of dissolved non-metals $(\mathrm{O}, \mathrm{C}, \mathrm{N}, \mathrm{H})$ in the material and particulary in the liquid metal can be the most important parameters of the corrosion reactions. The pxrhange of elements of this group can exceed the corrosion caused by dissolution of metallic components of the a11oy $/ 4 /$.

In the recent years several experiments are carried out with couples of interesting materials and liquid lithium /5,6/. From these tests the conclusion was drawn, that LME in the classical sense (surface active process) would not appear in lithium. The occurance of LME was expected for only a limited number of reaction pairs, for instance low carbon steels in lithium. Corrosion reactions as intercrystalline dissolution and grain boundary penetration are more favoured in liquid alkali metals. Therefore, research on the compatibility of metallic materials with liquid lithium was mainly directed to long-time high-temperature tests. LME does not occur within this field of parameters.

'lhe degree of purity of the lithium is very important. Purification techniques have to be applied. Very sensitive methods to estimate the impurity contents have to be used. The contents of nitrogen and oxygen can be detected by gettering with metals as titanium and analysis the getter foils. The chemical activities of carbon and nitrogen are determined by means of the foil equilibration method, which uses stainless steel foils (AISI 304) as monitor for the non-metals /7,8/. The content of carbon was $<5 \mathrm{ppm}$ and of nitrogen $<200 \mathrm{ppm}$ in our tests. Thus, the experiments were carried out in a weak contaminated lithium.

\subsection{Progress of Experiments}

The tensile tests in air as well as in lithium were performed by means of an INSTRON TTDML tensile machine with a 2,5 t frame.

Before testing, the specimens of the three materials were cleaned in an acetone bath by ultrasonics and heat treated in vacuo. The in-lithium tests needed some special preparing actions. They had to be mounted into capsules inside a purified argon gloverbox. The filling with molten lithium and closure of the capsules had also to be done within the protective atmosphere. Some of the tensile specimens have been pre-exposed within capsules filled with lithium or argon for $1000 \mathrm{~h}$ at $550^{\circ} \mathrm{C}$ in order to study the effect of such a pre-treatment on the material behaviour in tensile tests. The atmosphere in the glove-box was argon of $99,999 \%$ purity $\left(2,2 \mathrm{vpm} \mathrm{N} \mathrm{N}_{2}, 1,6 \mathrm{vpm} 0_{2}\right)$ to be kept at this level of purity by means of a purification unit.

The strain rate was one of the parameters varied in our tests. Since the machine allowed the variations only in larger steps, we made the choice of the two rates:

$$
\mathrm{v}_{\mathrm{ml}}=50 \mathrm{~mm} / \mathrm{min}, \mathrm{v}_{\mathrm{m} 2}=1 \mathrm{~mm} / \mathrm{min}
$$

for all specimens. The resulting strain rates were:

$$
\varepsilon_{1}=2,7810^{-2} \mathrm{~s}^{-1}, \varepsilon_{2}=5,5610^{-4} \mathrm{~s}^{-1}
$$

for the specimens with a gauge length of 30 num (1.4914) and:

$$
E_{1}=4,1710^{-2} \mathrm{~s}^{-1}, \varepsilon_{2}=8,3310^{-4} \mathrm{~s}^{-1}
$$

For the other specimens with a gauge length of $20 \mathrm{~mm}(1.4301$ and 1.4923).

The total elongation at fracture and the reduction of area were measured by examination of the specimens. The values of the yield strength and the ultimate tensile strength were derived from the stress-strain diagram of each test. Some of the specimens underwent more detailed examination procedures as metallography and scanning electron microscopy.

\section{Results}

Among the data gained in the tensile tests the reduction of area is a characteristic property to indicate an occuring embrittlement of materials. The values of the reduction of area are, therefore, compared in the Figs. 1-3 for the three materials. The influence of the environment -air or lithium- on the strength of the steels was little. 


\subsection{The Austenitic Steel}

The steel AISI 304 does not show detectable differences of the measured properties (yield strength $R_{1}=120-150 \mathrm{MPa}$, ultimate tensile strength $\mathrm{R}_{\mathrm{m}}=400 \mathrm{MPa}$, reduction of area $\mathrm{Z}=75 \%$ ) caused $\mathrm{Pby}$ the action of lithium during the tensile tests. The pre-treatment in argon atmosphere does not cause any change of the values. The specimens pre-exposed in 1 ithium show a sensitization effect. While tensile tests in air do not result differently from the above mentioned values, the tensile tests in lithium reveal clear evidence for embrittlement. The reduction of area decreases to values around $Z=30 \%$. The results are confirmed by some repeated tests.

The ductile specimens do not indicate changes of the microstructure. The fracture mode is a dimple fracture (cup and cone) in all cases. After the pre-exposure in 1 ithium an increasing number of precipitations along grain boundaries is detectable. After the tensile tests in lithium more and longer surface cracks are present. These cracks grow into the specimens along grain boundaries. This intergranular brittle fracture is an indication of an embrittlement.

\subsection{The Martensitic Steels}

The two martensitic steels show a similar behaviour when tensile tested in liquid 1ithium. As indicated by the results of these tests, the specimens of the steels are somewhat sensitive to LME even without any pre-exposure in lithium. The LME-effect is clearly detected by the comparison of values of reduction of area (1.4923: $\mathrm{R}=600 \mathrm{MPa}, \mathrm{R}=750 \mathrm{MPa}, \mathrm{Z}=55 \%$ and $1.4914: R_{=}=600 \mathrm{MPa}, R_{=}=650 \mathrm{MPa}, \mathrm{Z}=70 \%$ ). The largest effect is observed in the test of steel 1.4983 at $200{ }^{\circ} \mathrm{C}{ }^{\mathrm{tm}}(\mathrm{z}=40 \%)$. The effect measured at $250{ }^{\circ} \mathrm{C}$ shows that the temperature range of LME covers also this higher level (1.4914: $Z=40$ res. $50 \%$ ).

Pre-exposure in 1 ithium promotes the LME-effect as in the case of steel AISI 304 . The specimens tested in lithium show a brittle fracture mode. The steel 1.4923 ( $Z=15 \%$ is embrittled to a higher degree than the steel $1.4914(Z=30 \%)$. The metallurgical examination of the specimens reveals carbide precipitations in the outer zones as well as large surface cracks. The failure occurs in a mixed Fracture mode. Intercrystalline brittle fracture is one component, ductile slip fracture the other.

\section{Discussion and Conclusions}

The effect of 1 ithium on the materials has to be devided into two seperate processes. In the tensile tests at $200-250{ }^{\circ} \mathrm{C}$ the contact time is short. Diffusion processes cannot take part due to the low temperature and the short time. The effect of lithium in the tensile tests should be considered to be of physical nature as is claimed for the LME. The pre-exposure of $1000 \mathrm{~h}$ duration at $550^{\circ} \mathrm{C}$ enables the lithium to react chemically with the steels by leaching of metallic elements as well as by exchange of non-metals. Metallurgical changes occur in the steels, since diffusion can take place at the level of $550{ }^{\circ} \mathrm{C}$ and the exposure time is sufficient for carbide precipitation.

The attack of lithium on the steels in the tests has to be considered under those aspects. The reactions of lithium are based on grain boundary effects in all the steels tested. The metallurgical state of the grain boundaries - more or less dense chains of precipitated carbides- influences the extent of the grain boundary attacks. Thus, the explanation of different effects can be given on a comparison of the carbide precipitates.

The austenitic steel in the solution annealed state does not show any sensitivity against LME in Iithium. The metallurgical state cannot be markedly changed at $200-250{ }^{\circ} \mathrm{C}$ in a short time. The pre-exposure sensitizes the steel AISI 304 . The material containing grain boundary carbides of the $\mathrm{Me}_{6} \mathrm{C}_{23}$ type does not show brittle fracture in tensile tests in air at 200-250 $\mathrm{C}$. The contact ${ }^{2} 23$ of the surfaces of tensile specimens with liquid lithium in the same temperature range causes, however, brittle behaviour. Thus, the austenitic steel exhibits a dependence of its sensitivity against LME on the metallurgical state.

The complex structure of the two martensitic steels makes them sensitive against LME in lithium even without any pre-treatment. The amount of grain boundary precipitates seems to be sufficiently high to cause this sensitivity. These materials also have a low stacking fault energy, which may cause additional stress peaks, since additional dislocations are able to restrict a cross slip.

The observed effects of lithium on the three materials are in relationship to some conditions necessary for the occurance of LME:

- the embrittlement occurs in the vincinity of the melting point of the liquid metal;

- the fracture mode is intercrystalline (reaction controlled by the embrittler);

- the liquid embrittler atom has to be present at the crack tip (adsorption induced reaction).

The adsorption of lithium atoms on the clean material surface as well as on fresh sur- 
face areas in the cracks is due to the fact that lithium removes passivation layers by chemical reduction of oxides of heavy metals. The sensitation of grain boundaries by preceding lithium corrosion may be caused by the formation of compounds -chromium carbides or carbonitides-, which react with liquid lithium with high reaction rates even at the low temperature level of the tensile tests. The leaching of substitional elements proceeds mainly along grain boundaries. This corrosion effect may have opened the path for lithium to penetrate the grain boundaries. Thus, the rate of removal of precipitates out of the grain boundaries is raised markedly by the lithium pre-corrosion.

The austenitic steel, which is relatively unsensitive against LME, needs the pre-corrosion before LME can occur. The martensitic steels behave more or less as brittle materials in tensile tests under lithium environment. Their susceptibility to LME is, however, increased by the pre-corrosion in liquid lithium. The progress of damage of the materials occurs along grain boundaries containing precipitates or segregates, which are dissolved by lithium. Thus, intergranular fracture initiates the rupture of the specimens, which normally behave ductile.

\section{Acknowledgement}

We gratefully acknowledge the contributions of Mrs. Perich, Mr. Drechsler and Mr. Frees to the experimental work.

\section{References}

/1/ KamDAR, M.H., "Embrittlement by Liquid Meta1s", Materials Science Vol. 15, No. 4 Pergamon Press, New York 1973

/2/ SHUNK, F.A., WARKE, W.R., "Specificity as an Aspect of Liquid Metal Embrittlement", Scripta Met. 8, 519-526 (1974).

3/ ANDERKO, K., DAVID, K., OHLY, W., SCHIRRA, M., WASSIlEW, C., "Optimization Work on Niobium stabilized $12 \%$-Cr Martensitic Steel for Breeder and Fusion Reactor Applications", Top. Conf. on Ferritic Alloys for Use in Nuclear Energy Technologies, Snowbird, Utah, June 19-23, 1983

14/ LEAVENWORTH, H., CLEARY, R.E., BRATTON, W.D., "Solubility of Structual Materia1s in Lithium", PWAC-356 (1961).

15/ CHOPRA, 0.K., "Effects of Sodium and Lithium Environment on Mechanical Properties of Ferrous Alloys", J. of Nuc. Mat. 115, 223-238 (1983).

/6/ SPENCER, R.E., MATLOCK, D.K., OLSON, D.L., "The Effects of Liquid Metal Embrittlement on High Temperature Fatigue of 2.25Cr-1Mo Steel in Liquid Lithium", J. Mat. for Energy Systems 4, 187-194 (1983).

17/ BORGSTEDT, H.U., "Materials Problems araising from Impurity Gettering of Lithium by Zirconium or Titanium", J. of Nuc. Mat. 103\&104, 693-698 (1981).

18/ KONYS, J., "Estimation of Carbon and Nitrogen in Lithium by the Foil Equilibration Method", Proc. of the 3rd Int. Conf. on Liquid Metal Engineering and Technology in Energy Production, Oxford, U.K., Apri1 9-13, 1984 
Fig. 1. Reduction of area (Z) in tensile tests of the martensitic steel 1.4914; influence of environment, temperature and strain rate

Fig. 2. Reduction of area ( $\mathrm{Z}$ ) in tensile tests of the martensitic steel 1.4923; influence of environment, temperature and strain rate
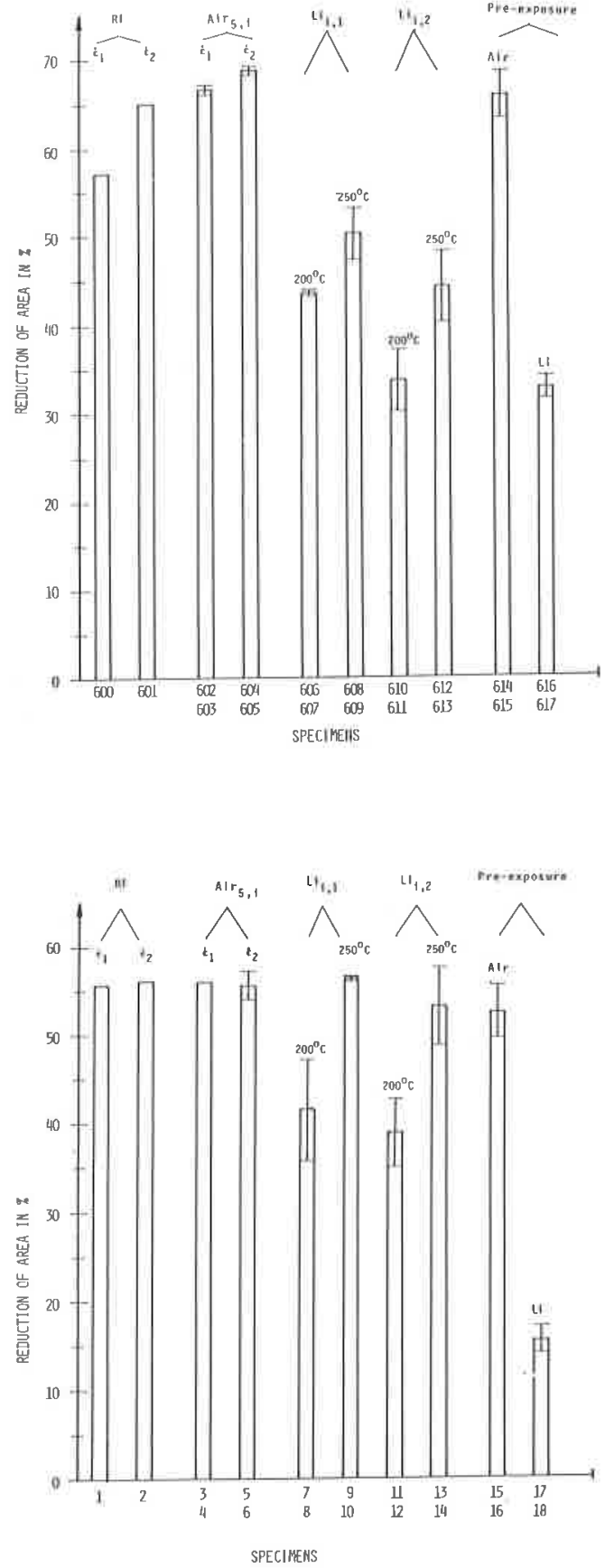
Fig. 3. Reduction of area ( $Z$ ) in tensile tests of the austenitic steel 1.4301; influence of environment, temperature and strain rate

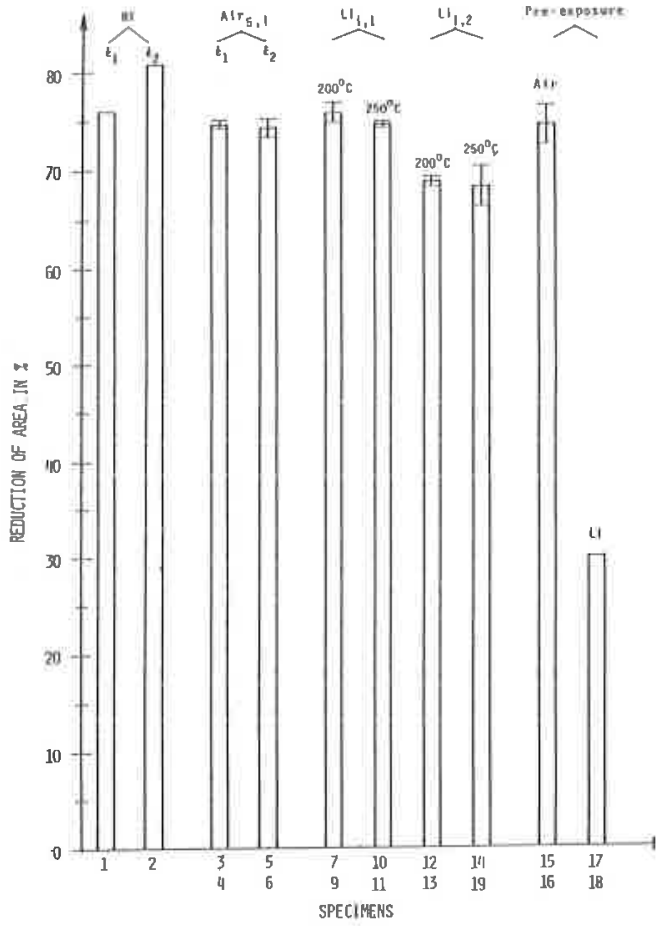

